\title{
Within-subjects assessment of the within-compound associations resulting from intermixed and blocked preexposure schedules
}

\author{
Gabriel Rodríguez • Gumersinda Alonso
}

Published online: 21 November 2014

(C) Psychonomic Society, Inc. 2014

\begin{abstract}
Nonhungry rats received training consisting of intermixed presentations of a compound flavor and an element of that compound ( $\mathrm{AX}, \mathrm{X}, \mathrm{AX}, \mathrm{X}, \ldots$ ), and then a separate block of presentations of another compound (BX, BX, BX, ...). Stimuli A and B were two odor solutions (almond and vanilla), and stimulus $\mathrm{X}$ was a highly concentrated solution of sucrose. After training, a state of hunger was induced in the rats, and their consumption levels of $\mathrm{A}$ and $\mathrm{B}$ alone were tested. We found higher test consumption of B than of A (Exp. 1). We interpreted these differences as indicating that the $\mathrm{B}-\mathrm{X}$ association had become stronger than the $\mathrm{A}-$ $\mathrm{X}$ association as a result of the training. In Experiment 2, we demonstrated that the presence of $\mathrm{X}$ during training was necessary for that effect to appear (Exp. 2). These results give support to the recent proposal that within-compound associations are maintained better by blocked than by intermixed preexposure (Rodríguez \& Alonso, 2014). We discuss the implications of this difference for explaining the intermixed-blocked perceptual-learning effect.
\end{abstract}

Keywords Perceptual learning - Intermixed-blocked · Within-compound association · Preexposure $\cdot$ Rats

The way that a stimulus is perceived may change as a consequence of exposure to it. An instance of this perceptuallearning phenomenon is the observation that exposure to two similar stimuli can enhance their discriminability (e.g., Gibson \& Walk, 1956). A line of animal research has investigated this type of perceptual-learning effect over recent years, using rats as subjects and flavors as the critical stimuli. For instance, Symonds and Hall (1995, Exp. 2) gave

G. Rodríguez $(\varangle) \cdot \mathrm{G}$. Alonso

Universidad del País Vasco (UPV-EHU), San Sebastián, Spain

e-mail: gabriel.rodriguez@ehu.es rats preexposure to two flavor compounds, $\mathrm{AX}$ and $\mathrm{BX}$, in intermixed trials ( $\mathrm{AX}, \mathrm{BX}, \mathrm{AX}, \mathrm{BX}, \ldots$. . . Control subjects received an equivalent amount of preexposure to the stimuli, but in separate blocks of trials (e.g., AX, AX, ..., BX, BX, ...). For all subjects, an aversion was then established to $\mathrm{AX}$, and generalization to BX was tested. It was found that the rats given intermixed preexposure showed less generalization (i.e., better discrimination) between $\mathrm{AX}$ and $\mathrm{BX}$ than did those that received blocked preexposure. This outcome is referred to as the intermixed-blocked effect and has been demonstrated in a wide variety of conditions with both nonhuman animals (e.g., Bennett \& Mackintosh, 1999; Blair \& Hall, 2003; Honey, Bateson, \& Horn, 1994; Rodríguez \& Alonso, 2004) and humans (e.g., Dwyer, Hodder, \& Honey, 2004; Lavis \& Mitchell, 2006; Mundy, Honey, \& Dwyer, 2007; Nelson \& Sanjuan, 2009).

The intermixed-blocked effect has commonly been interpreted as indicating that an intermixed schedule may enhance the discriminability of stimuli. However, the nature of the learning mechanism, or mechanisms, responsible for these changes in discriminability is currently a matter of theoretical debate (for a recent review, see Mitchell \& Hall, 2014). One of the most accepted explanations for the effect is in terms of changes in the salience of the stimulus features. Specifically, several authors have suggested different salience modulation mechanisms by which intermixed preexposure might enhance the attention paid to (i.e., the salience of) the distinguishing features of the stimuli.(e.g., Hall, 2003; McLaren \& Mackintosh, 2000). Recently, we have proposed and tested an alternative (or complementary) associative explanation to this salience modulation account (Rodríguez \& Alonso, 2014). The starting point for our account is that preexposure to $\mathrm{AX}$ and $\mathrm{BX}$ allows the establishment of $\mathrm{X}-\mathrm{A}$ and $\mathrm{X}-\mathrm{B}$ within-compound associations (e.g.,Rescorla \& Cunningham, 1978). These associations constitute a source of mediated generalization between the preexposed stimuli. 
The $\mathrm{X}-\mathrm{A}$ association will allow activation of $\mathrm{A}$ on the $\mathrm{BX}$ trials, and this may contribute to treating $\mathrm{BX}$ as being more similar to AX. Similarly, the X-B association will allow associative activation of $\mathrm{B}$ on the $\mathrm{AX}$ trials, which may contribute to AX being treated as more similar to BX. The intermixed-blocked effect could emerge because the contribution of mediated generalization on test performance may be less after intermixed than after blocked preexposure. Specifically, we propose that the within-compound associations are established better with blocked than with intermixed preexposure (see McLaren \& Mackintosh, 2000, for an alternative account in terms of the formation of stronger inhibitory links between the unique features of the stimuli in the intermixed than in the blocked condition).

We tested our hypothesis in a series of between-subjects experiments in which we first confirmed our previous demonstration (Rodríguez \& Alonso, 2004, 2008; Rodríguez, Lombas, \& Alonso, 2009) that intermixed preexposure to a flavor compound and to an element of that compound (AX, X, $\mathrm{AX}, \mathrm{X}, \ldots$. .) reduces the generalization between them to a greater extent than does equivalent blocked preexposure (AX, $A X, \ldots, X, X, \ldots$, or $X, X, \ldots, A X, A X, \ldots$ ). In two further experiments, we assessed the strength of the $\mathrm{X}-\mathrm{A}$ withincompound association resulting from the preexposure conditions involved in this demonstration of the intermixedblocked effect. In one of these experiments, we employed a sensory preconditioning procedure in which we gave rats either intermixed or blocked preexposure to $\mathrm{AX}$ and $\mathrm{X}$ before aversive conditioning to $\mathrm{A}$. On a subsequent test in which $\mathrm{X}$ was presented, it was found that rats preexposed to AX and $\mathrm{X}$ in separate blocks of trials showed more aversion to $\mathrm{X}$ than did rats preexposed to the stimuli in an intermixed fashion (Rodríguez \& Alonso, 2014, Exp. 2). We interpreted this finding as indicating that the $\mathrm{X}-\mathrm{A}$ within-compound association became stronger after the blocked than after intermixed preexposure to $\mathrm{AX}$ and $\mathrm{X}$. On testing with $\mathrm{X}$, a stronger $\mathrm{X}-\mathrm{A}$ association following blocked preexposure would have allowed for more effective activation of the representation of the US, via the $\mathrm{X}-\mathrm{A}-\mathrm{US}$ associative chain. We found additional evidence supporting this interpretation in a further experiment using a conditioned flavor preference procedure (Rodríguez \& Alonso, 2014, Exp. 3). In this experiment, nonhungry rats received either intermixed or blocked preexposure to AX and X. In order to establish a conditioned preference during the preexposure phase, a solution of almond was used as stimulus X (which served as the conditioned stimulus; CS), and a highly concentrated sucrose solution as stimulus A (which, given its nutrient properties, served as the unconditioned stimulus, US). On a subsequent test in which the rats were in a state of hunger, a higher consumption of $\mathrm{X}$ was observed (which indicated a stronger conditioned preference-i.e., a stronger $\mathrm{X}-\mathrm{A}$ association) after blocked preexposure than after intermixed preexposure to $\mathrm{AX}$ and $\mathrm{X}$.
This set of results gives support to our hypothesis that the intermixed-blocked perceptual-learning effect might be due, at least in part, to the differential impacts of these schedules on the establishment of within-stimulus learning. An implication of this hypothesis is that the superiority of the blocked schedule in promoting within-stimulus learning should be evident in other conditions in which the intermixed-blocked effect is found. This was the case for the paradigm used by Hall et al. (2006), Exp. 1a; see also Blair \& Hall, 2003), which was a within-subjects version of the design employed by Rodríguez and Alonso (2004, 2014). During the preexposure phase of Hall et al.'s (2006) experiment, rats received presentations of two compounds, $\mathrm{AX}$ and $\mathrm{BX}$, and the common element of these compounds, $\mathrm{X}$. Presentations of AX were alternated with presentations of $X$ (intermixed), whereas all presentations of BX were given in a separate block of trials. Rats then received aversive conditioning to $\mathrm{X}$ after preexposure. On a subsequent test, it was observed that the aversion conditioned to X generalized less readily to AX (the compound intermixed with $\mathrm{X}$ during preexposure) than to $\mathrm{BX}$ (the compound preexposed in a separate block of trials). According to our hypothesis, this perceptual-learning effect must be due, at least to some extent, to the formation of stronger within-compound associations between the elements of the compound preexposed in a block of trials (BX) than between the elements of the compound presented in alternation with $\mathrm{X}(\mathrm{AX})$. Next, we present two experiments that were designed to test this notion (for a summary of the experimental designs, see Table 1).

With the exception of the stimuli used, our experimental groups (IB and $\mathrm{BI}$ ) received a preexposure phase identical to that used in the experiment by Hall et al. (2006, Exp. 1a). Group IB first received intermixed presentations of AX and X, followed by a block of presentations of BX. Group BI received the opposite sequence of presentations. With the aim of exploiting a conditioned flavor preference procedure similar to that employed in our previous study (Rodríguez \& Alonso, 2014, Exp. 3), we used two solutions of almond and vanilla as

Table 1 Experimental designs

\begin{tabular}{lll}
\hline Group & Preexposure & Test \\
\hline Experiment 1 & & \\
IB & $4(\mathrm{AX}, \mathrm{X}), 4 \mathrm{BX}$ & $\mathrm{A}, \mathrm{B}$ \\
BI & $4 \mathrm{BX}, 4(\mathrm{AX}, \mathrm{X})$ & $\mathrm{A}, \mathrm{B}$ \\
Experiment 2 & & \\
IB & $4(\mathrm{AX}, \mathrm{X}), 4 \mathrm{BX}$ & $\mathrm{A}, \mathrm{B}$ \\
IB-no X & $4(\mathrm{~A}, \mathrm{~W}), 4 \mathrm{~B}$ & $\mathrm{~A}, \mathrm{~B}$ \\
BI & $4 \mathrm{BX}, 4(\mathrm{AX}, \mathrm{X})$ & $\mathrm{A}, \mathrm{B}$ \\
BI-no X & $4 \mathrm{~B}, 4(\mathrm{~A}, \mathrm{~W})$ & $\mathrm{A}, \mathrm{B}$ \\
\hline
\end{tabular}

A and $\mathrm{B}=2 \%$ vanilla and $2 \%$ almond, counterbalanced; $X=20 \%$ sucrose; $\mathrm{W}=$ water 
the stimuli A and B (counterbalanced) and a strong (20\%) solution of sucrose as stimulus X. After preexposure, a state of hunger was induced in the rats, and they were tested with both $\mathrm{A}$ and $\mathrm{B}$. We expected that this test would reflect the association of $\mathrm{A}$ and $\mathrm{B}$ with $\mathrm{X}$ (i.e., with the highly concentrated sucrose). In particular, we expected that the A-sucrose and Bsucrose associations would be expressed as a tendency to increase the consumption of A and B on test. Thus, another novel feature of the present study was that we assessed the strength of the within-compound associations by testing the ability of the unique features of the compounds (A and B) to activate the representation of the common feature $(\mathrm{X})$, rather than the ability of this common feature to activate the representation of the unique features, as was the case in our previous study (Rodríguez \& Alonso, 2014). If, as has been suggested (e.g., by Rescorla \& Freberg 1978), the withincompound associations established between two flavors presented simultaneously are symmetrical, then in the present within-subjects experiments we should find an effect parallel to that observed in our previous between-subjects studies. That is to say, we were expecting to observe more test consumption of $\mathrm{B}$ than of $\mathrm{A}$, indicating that the association of $\mathrm{B}$ with the sucrose was stronger than that of A with the sucrose.

Finally, a further novel feature of the present study with respect to our previous work (Rodríguez \& Alonso, 2014) was the addition of further control conditions in Experiment 2. In these conditions (the no-X groups), presentations of $\mathrm{AX}$ and $\mathrm{BX}$ were replaced by presentations of A and B, respectively, and presentations of $\mathrm{X}$ alone were replaced by presentations of water. The omission of the presentations of the sucrose (i.e., $\mathrm{X}$ ) in these groups would allow us to establish more firmly that any difference observed in the experimental groups indeed reflected differences in the extents to which the test stimuli (A and B) were associated with the sucrose.

\section{Experiment 1}

During the training phase of this experiment (for a summary of the experimental design, see Table 1), all rats received presentations of AX, BX, and X. Throughout all of this phase, the subjects had continuous access to food, but access to fluids was restricted to two daily periods. All rats received four days of training, on each of which AX was presented on one of the drinking periods, and $\mathrm{X}$ was presented on the other. In addition, they also received 2 days of training in which BX was presented on both drinking periods. There were two groups of rats. Group IB first received $\mathrm{AX}$ and $\mathrm{X}$ in an intermixed fashion, followed by BX in a block of trials. Group BI received the opposite arrangement. After the training phase, a state of hunger was induced in the rats, and they were tested with both $\mathrm{A}$ and $\mathrm{B}$. We expected to observe more consumption of $\mathrm{B}$ than of $\mathrm{A}$, which would indicate that, as a result of preexposure, the $\mathrm{B}-\mathrm{X}$ (i.e., the $\mathrm{B}-$-sucrose) association was stronger than that between $\mathrm{A}$ and $\mathrm{X}$ (i.e., the $\mathrm{A}$-sucrose association).

With the exception of the stimuli used, the conditions of our training phase were identical to those of the preexposure procedure employed by Hall, Blair, and Artigas (2006, Exp. 1a). This intermixed-blocked effect was found to be independent of the order in which the two preexposure schedules were presented (i.e., whether the block of presentations of BX was presented over the first or last 2 days of training). If this perceptual-learning effect is fostered by differences in the strengths of the within-compound associations established during preexposure, then we should find evidence of a stronger within-compound association between the elements of the compound presented in a block of trials (BX) than between the elements of the compound presented in alternation with $\mathrm{X}$ (AX). That is to say, we were expecting to observe more test consumption of $\mathrm{B}$ than of $\mathrm{A}$.

\section{Method}

Subjects and apparatus All procedures relating to the maintenance and use of animals were in accordance with the European Law of Animal Welfare and were approved by the Animal Welfare Committee of the University of the Basque Country (UPV/EHU).

The subjects were 16 male Wistar rats with a mean ad lib weight of $336 \mathrm{~g}$ at the start of the experiment. They were singly housed, with continuous access to food, in a colony room that was artificially lit from 8:00 a.m. to 8:00 p.m. each day. Access to water was restricted as detailed below.

The solutions used as experimental stimuli were administered in the home cages at room temperature in 50-ml plastic centrifuge tubes, each equipped with a rubber stopper to which was fitted a stainless steel, ball-bearing-tipped spout. The following flavored solutions were used: sucrose, $20 \%$ $(\mathrm{w} / \mathrm{w})$; vanilla, $1 \%(\mathrm{w} / \mathrm{v}$; vanilla flavoring supplied by SuperCook, Leeds, UK); and almond, 2\% (w/v; SuperCook almond flavoring). For half of the subjects, stimulus A was vanilla and stimulus B was almond; for the remainder, this arrangement was reversed. For all of the subjects, $\mathrm{X}$ was sucrose. Consumption was measured by weighing the tubes before and after trials to the nearest $0.1 \mathrm{~g}$.

Procedure The water deprivation regime was initiated by removing the standard water bottles overnight. On each of the following 4 days, access to water was restricted to two daily sessions of $30 \mathrm{~min}$, at 1:00 p.m. (the afternoon session) and 6:00 p.m. (the evening session). The presentations of fluids continued to be given at these times throughout the experiment. 
After the water deprivation schedule had been established, the rats were randomly assigned to one of two equal-sized groups, the IB or the BI group (see Table 1), before the start of the training phase. This phase lasted for 6 days. All subjects received four presentations of each of the flavors $\mathrm{AX}, \mathrm{BX}$, and $\mathrm{X}$. The rats in Group IB were first given 4 days of alternating trials of $\mathrm{AX}$ and $\mathrm{X}$, with $10 \mathrm{ml}$ of one being presented during the afternoon session and $10 \mathrm{ml}$ of the other being presented during the evening session. For half of these rats, AX was the afternoon stimulus and $\mathrm{X}$ was the evening stimulus; for the rest, the arrangement was reversed. The next 2 days consisted of a block of presentations of BX, in which $10 \mathrm{ml}$ of this flavor was made available in both the afternoon and evening drinking sessions. The rats in Group BI were treated identically, except that they received the blocked presentations of BX on the first 2 days of the phase, followed by 4 days of AX and $\mathrm{X}$.

After the last training trial (on the evening of the sixth day of training), the rats were allowed free access to water but food was removed, so that they had been food-deprived for $19 \mathrm{~h}$ by the first test session on the following morning. The rats were deprived of water $3 \mathrm{~h}$ before this test, which consisted of a 30min period of access to the A solution for half of the rats, and to the B solution for the remaining subjects. After this first test, the rats were given free access to water and $12 \mathrm{~g}$ of food. On the next morning, the rats were deprived of water $3 \mathrm{~h}$ before the second test. Rats that had been tested with $\mathrm{A}$ on the previous day were given a test trial with $\mathrm{B}$, and vice versa.

Data analysis The data were analyzed with an analysis of variance (ANOVA) using type III sums of squares. A criterion of statistical significance of $p<.05$ was adopted. A $t$ test was used for pairwise comparisons. Effect sizes for the ANOVA are reported as partial eta-squared values, and as Cohen's $d$ for pairwise comparisons.

\section{Results and discussion}

We found some evidence of neophobia on the first two trials of the training phase, with the animals in both groups failing to drink the full amount offered; the group means for consumption on these two first trials were 7.8 and $7.9 \mathrm{ml}$ for Group IB, and 8.2 and $7.7 \mathrm{ml}$ for Group BI. Thereafter, all of the animals drank almost the full amount on all the preexposure trials. During the training phase, the group means for consumption of AX per trial were 8.9 and $8.6 \mathrm{ml}$ for Groups IB and BI, respectively. The equivalent means for consumption of $\mathrm{BX}$ were 9.1 and $8.8 \mathrm{ml}$. The mean scores for consumption of $\mathrm{X}$ alone were 9.2 and $9 \mathrm{ml}$ for Groups IB and BI, respectively. An ANOVA was conducted on these scores, with the variables being the order of the intermixed and blocked subphases of training (Group IB vs. BI), the counterbalancing (A and B as vanilla or almond), and flavor (AX, BX, X), and this produced no significant effects (all $F_{\mathrm{S}}>1$ ).
The group means for test consumption of flavors A and B are shown in Fig. 1. It is clear that consumption was higher for $\mathrm{B}$ than for $\mathrm{A}$ in both groups, and this difference was particularly marked in Group IB. An ANOVA with flavor (A or B) as a within-subjects variable, and the order of the intermixed and blocked subphases of training (Group IB vs. BI) and counterbalancing ( $A$ and $B$ as vanilla or almond) as between-subjects variables produced a significant effect of flavor, $F(1,12)=7.80, \eta_{p}{ }^{2}=.39$. No other main effect or interaction was significant $\left(F_{\mathrm{s}}<3.69, p \mathrm{~s}>.08\right)$.

These results indicate that during the training phase, $\mathrm{B}$ became more strongly associated with the sucrose (X) than A. These results are thus consistent with our previous findings obtained with between-subjects designs (Rodríguez \& Alonso, 2014, Exps. 2 and 3), and confirm differential effects of the intermixed and blocked schedules on establishing within-compound associations. The association between the elements of a simultaneous compound seems to be maintained better when the compound is presented in a block of trials $(\mathrm{BX}, \mathrm{BX}, \ldots)$ than when it is intermixed with additional presentations of one of their elements presented alone (AX, X, AX, X, . .).

\section{Experiment 2}

The aim of this experiment was to confirm the reliability of the schedule effect found in Experiment 1, while including further control conditions. As Table 1 shows, we replicated the treatment given to the IB and BI groups of Experiment 1, and we

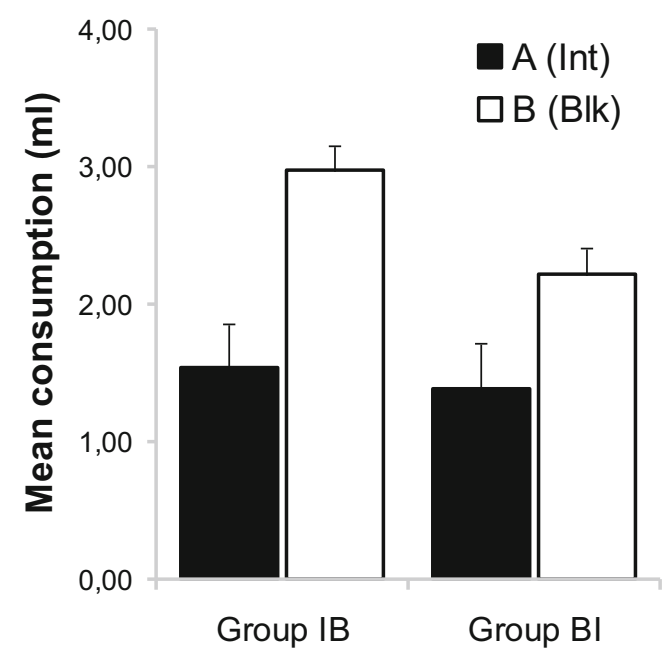

Fig. 1 Experiment 1: Mean test scores for consumption of A and B after they have been presented in compound with $X$ (sucrose) during the preexposure. The rats in Group IB first received alternated (intermixed) trials with $\mathrm{AX}$ and $\mathrm{X}$, and then a block of BX trials. The rats in Group BI received initial preexposure to the block of $\mathrm{BX}$ trials and then alternating (intermixed) trials with AX and X. Vertical bars represent within-subjects standard errors, computed on scores adjusted for variation between the subjects (Bakeman \& McArthur, 1996) 
added two further groups (to be referred to as the no-X groups). In these control groups, presentations of $\mathrm{AX}$ and $\mathrm{BX}$ were replaced by presentations of $\mathrm{A}$ and $\mathrm{B}$, respectively; and presentations of $\mathrm{X}$ alone were replaced by presentations of water. We have assumed that the effect seen in Experiment 1, the greater consumption of $\mathrm{B}$ than of $\mathrm{A}$ on test, is a consequence of differences in the strength of the within-compound associations involving those stimuli. The no-X groups of the present experiment would allow us to rule out some alternative explanations. For example, it might be of some importance that the training procedure used in Experiment 1 involved presentations of BX twice a day, whereas AX was presented once a day. In particular, it might be argued that these differences in the intervals between the stimulus presentations might have generated differences in the rates at which neophobia habituated to A and B. That is, it could be that the outcome that we observed in Experiment 1 might reflect a less habituated neophobic response to A than to B. If this is true, whether or not $\mathrm{X}$ was presented during the training phase would not be a relevant factor in determining greater test consumption of $\mathrm{B}$ than of $\mathrm{A}$.

The addition of the no-X groups would also help us rule out an alternative explanation for our effect in terms of greater generalization between B and X than between A and X. Hall et al. (2006) presented evidence suggesting that preexposure training similar to that received by groups IB and $\mathrm{BI}$ in Experiment 1 results in A becoming more salient than B. Although this does not seem the most likely possibility, it might be that in Experiment 1, from the beginning, A and B (almond or vanilla, counterbalanced) shared a sufficient amount of elements with $\mathrm{X}$ (a strong solution of sucrose) to ensure a substantial degree of generalization among them. In that case, the greater test consumption of B than of A could have reflected the fact that the animals more readily discriminated the more salient A than the less salient B from X. In other words, according to this account, the animals would have showed more test consumption of $\mathrm{B}$ than of $\mathrm{A}$ because they were more likely to respond to $\mathrm{B}$ than to $\mathrm{A}$ as if it was the appetitive flavor X. An implication of this account is that some sign of this supposed stimulus generalization should be evident in the no-X groups. That is, one would expect to observe a reduction in the consumption of $\mathrm{A}$ in the experimental groups (which would indicate reduced generalization between $\mathrm{A}$ and $\mathrm{X}$ as a result of the high salience of $\mathrm{A}$ ) with respect to a relatively higher consumption of both $\mathrm{A}$ and $\mathrm{B}$ in the no- $\mathrm{X}$ groups, and of $\mathrm{B}$ in the experimental groups (which would indicate that the animals were treating, to some extent, $\mathrm{A}$ and $\mathrm{B}$ as if they were the sucrose). The pattern of results expected according to our hypothesis that the $\mathrm{B}-\mathrm{X}$ withincompound association is stronger than the $\mathrm{A}-\mathrm{X}$ association would be quite different. In this case, one would expect to observe an increase in the consumption of $\mathrm{B}$ in the experimental group (which would indicate an effective $\mathrm{B}-\mathrm{X}$ withincompound association) with respect to a relatively low consumption of A and B in the control groups (which would indicate a null activation of $\mathrm{X}$ ), and of $\mathrm{A}$ in the experimental groups (which would indicate weak activation of $\mathrm{X}$ as a result of a weak within-compound association).

\section{Method}

Subjects and apparatus The subjects were 32 male Wistar rats with a mean ad lib weight of $294 \mathrm{~g}$ at the start of the experiment. They were naive to all aspects of the present procedure. The housing and maintenance conditions were as we described for Experiment 1.

After water deprivation had been established, the subjects were randomly assigned to one of four equal-sized groups for the training phase: the two experimental groups (IB and $\mathrm{BI}$ ) and the two no-X control groups (IB-no-X and BI-no-X). For the rats in the experimental groups, the procedure was the same that was described in Experiment 1 . The rats in the control groups were treated identically to their corresponding experimental groups, except that they did not receive any presentation of sucrose during the training phase. In these control groups, presentations of AX and BX were replaced by presentations of $\mathrm{A}$ and $\mathrm{B}$, respectively, and presentations of $\mathrm{X}$ alone were replaced by presentations of $10 \mathrm{ml}$ of unflavored water. All other details were the same as in Experiment 1.

\section{Results and discussion}

The pattern of consumption observed during the training phase for the experimental IB and BI groups was highly similar to that observed in the previous experiment. No neophobia was evident in the no-X groups on the initial trials of the training phase. In these groups, rats consumed almost all of the fluid offered on all training trials. The mean scores for the consumption of A on these trials were 9.1 and $9.4 \mathrm{ml}$ for groups IB-no-X and BI-no-X, respectively. The equivalent means for the consumption of $\mathrm{B}$ were 9.2 and 9.5 for groups IB-no-X and BI-no-X, respectively.

The results of the test phase are presented in Fig. 2, which shows the group means for consumption of A and B. First, it can be observed that the experimental groups drank considerably more of B than of A. This difference confirms the withinsubjects effect observed in Experiment 1. Second, the no-X groups drank rather little of either flavor. This demonstrates that the different time intervals between the presentations of A and B during the training phase did not, in themselves, generate differences in test performance. This also indicates that the amount of generalization between the test stimuli and $\mathrm{X}$ was very small. The fact that the flavor effect (more consumption of B than of A) observed in the experimental groups was due to an increase in the consumption of $\mathrm{B}$ relative to the control groups supports the idea that a conditioned preference (an 


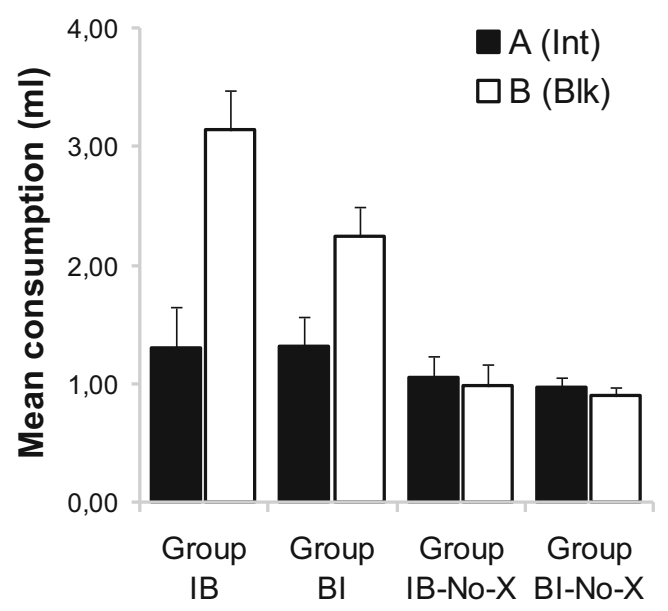

Fig. 2 Experiment 2: Mean test scores for consumption of A and B. The rats in Group IB received initial preexposure consisting of alternating (intermixed) trials with $\mathrm{AX}$ and $\mathrm{X}$, and a subsequent block of trials with BX. The rats in Group BI first received the block of BX trials and then the trials with $\mathrm{AX}$ and $\mathrm{X}$ presented in alternation (intermixed). The rats in the no-X groups received training identical to that received by Groups IB and $\mathrm{BI}$, but omitting the presentation of $\mathrm{X}$ (sucrose) during the preexposure. Vertical bars represent within-subjects standard errors, computed on scores adjusted for variation between the subjects (Bakeman \& McArthur, 1996)

association between B and the sucrose) was responsible for the effect. An ANOVA conducted on the data summarized in the figure, with the order of the intermixed and blocked subphases of training (Group IB vs. BI), the presence of X (whether or not X was presented during the training phase), and counterbalancing (A or B as vanilla or almond) as between-subject variables, and with flavor (A or B) as the within-subjects variable, confirmed all of these impressions. We found significant main effects of the presence of $X$ during the training phase, $F(1,24)=11.67, \eta_{p}{ }^{2}=$ 32, and of flavor, $F(1,24)=7.93, \eta_{p}{ }^{2}=25$, but no effects of either group or counterbalancing, $F_{\mathrm{s}}<1$. We also observed a significant interaction, $F(1,24)=9.67, \eta_{p}{ }^{2}=29$, between flavor and the presence of $\mathrm{X}$ during the training phase. No other interactions reached significance, $F_{\mathrm{s}}<3.32, p \mathrm{~s}>.08$. Further analyses carried out to explore the source of this interaction showed a flavor effect in the experimental groups, $t(15)=3.24$, $d=1.14$, thus replicating the effect reported in Experiment 1 . However, no difference was apparent between the consumption of $\mathrm{A}$ and $\mathrm{B}$ in the no-X groups, $t(15)<1$. Furthermore, whereas the experimental groups exhibited higher consumption of flavor B than did the control no-X groups, $t(30)=3.63, d=1.28$, no significant group differences emerged in the consumption of flavor $\mathrm{A}, t(30)=1.45$.

\section{General discussion}

The amount of generalization between two similar stimuli (e.g., AX and X) has been shown to be less after intermixed than after blocked presentations of them. This perceptuallearning effect has been demonstrated in experiments using either between-subjects (e.g., Rodríguez \& Alonso, 2004; Symonds \& Hall, 1995) or within-subjects (e.g., Blair \& Hall, 2003; Hall et al., 2006) comparisons. Recently, we have demonstrated that conditions able to generate a betweensubjects demonstration of the effect also differentially affect the strength of the within-compound associations (Rodríguez \& Alonso, 2014, Exps. 2 and 3). More specifically, we found that blocked preexposure to $\mathrm{AX}$ and $\mathrm{X}$ resulted in a stronger $\mathrm{X}-\mathrm{A}$ association than did intermixed preexposure to the stimuli. The two experiments reported here extend these previous findings to a within-subjects procedure. A training phase consisting of intermixed presentations of $\mathrm{AX}$ and $\mathrm{X}$ and an additional block of presentations of $\mathrm{BX}$ resulted in the formation of a $\mathrm{B}-\mathrm{X}$ association that was stronger than the $\mathrm{A}-\mathrm{X}$ association. Taken together, these and our previous results (Rodríguez \& Alonso, 2014) are compatible with an account of the intermixed-blocked effect in terms of different amounts of the mediated, or secondary (e.g., Hull, 1939), generalization supported by the within-compound associations.

It is widely assumed that generalization between two stimuli initially occurs only to the extent that they are similar- that is, to the extent that they have physical features in common. This source of generalization based on physical similarity is referred to as primary generalization. But it is also known that generalization may be supported by learned similarities between otherwise quite different stimuli (for a review, see Hall, 1991, pp. 161-179). For example, in the acquired equivalence phenomenon (e.g., Miller \& Dollard, 1941; Hall, 1996; Honey \& Hall, 1989), generalization between two quite dissimilar stimuli (e.g., A and B) is enhanced by prior training in which both stimuli are followed by, or presented with, the same outcome (e.g., X). This phenomenon may be explained by assuming that the stimulus representations consist of two types of elements. First, some representational elements are directly activated by their physical features (i.e., the A elements are activated by the A features, and the B elements are activated by the $\mathrm{B}$ features). And second, in other representational elements the stimuli may activate associatively (i.e., the $\mathrm{X}$ features). Following this assumption, learning of the $\mathrm{A}-\mathrm{X}$ and $\mathrm{B}-\mathrm{X}$ associations adds extra common features to the representations of $\mathrm{A}$ and $\mathrm{B}$ (i.e., the $\mathrm{X}$ elements), thus increasing the generalization between them. The mechanism that we suggest is responsible for the intermixed-blocked effect also appeals to this learned, or secondary, source of generalization. We assume that the formation of the within-compound associations during preexposure to the stimuli can make more similar the pattern of central representations activated by the presentation of the stimuli (e.g., Hall, 1991), and we propose that blocked preexposure is more effective than intermixed preexposure in fostering this enhancement of similarity, since 
it establishes stronger within-compound associations. For example, in our experiments, $\mathrm{X}$ would be more similar to BX than to $\mathrm{AX}$, because presentation of $\mathrm{X}$ would activate more strongly the B-representational elements (via the $\mathrm{X}-\mathrm{B}$ association) than the A-representational elements (via the $\mathrm{X}-\mathrm{A}$ association).

It seems reasonable to assume that the mechanism that we are invoking here will be especially relevant in determining the intermixed-blocked effect when the preexposed stimuli are relatively simple and quite dissimilar from the outset. In this case, detecting the common and the unique features would be easy, thus facilitating the formation of the withincompound associations between them. This may be the case in experiments of the sort presented here, in which rats are used as subjects and flavors as the stimuli (e.g., Bennett \& Mackintosh, 1999; Rodríguez \& Alonso, 2004; Symonds \& Hall, 1995). Following the same logic, it also seems quite plausible that the formation of within-compound associations would not have played a major role in other experiments involving much more complex and dissimilar stimuli. This might be the case in most of the human studies that have involved visual stimuli (e.g., Lavis \& Mitchell, 2006; Mundy et al., 2007). In these experiments, it is unlikely that the participants would have detected the unique stimulus features from the beginning of preexposure, which would make the formation and strengthening of any within-compound associations involving those features difficult. Under these circumstances, it seems more probable that the intermixed-blocked effect would have been generated by the ability of the intermixed schedule to enhance the salience of (and thus the detection of) the unique stimulus features (Mitchell \& Hall, 2014). It remains, however, to specify the role played by the within-compound associations in producing this enhancement of salience. Some accounts of the intermixed-blocked effect that appeal to mechanisms of salience modulation assume that intermixed preexposure maintains the strength of the withincompound associations more effectively than does blocked preexposure (i.e., just the opposite effect from the ones we observed here and in our previous study; Rodríguez \& Alonso, 2014). For example, Hall (2003) proposed that associative activation of a stimulus, in the absence of the stimulus itself, increases its salience or effectiveness. Hall (2003; see also Hall et al., 2006) applied this principle to the case in which two or more similar stimuli are presented. It was suggested that the formation of within-compound associations between the common and the unique features of a stimulus (e.g., the formation of the $\mathrm{X}-\mathrm{A}$ association during the presentations of the $\mathrm{AX}$ compound) allows associative activation (and thus an increase in salience) of the unique features on subsequent presentations of different stimuli containing those common features (e.g., on subsequent presentation of $\mathrm{X}$ alone, or BX, which would allow associative activation of $\mathrm{A}$ in its absence via the $\mathrm{X}-\mathrm{A}$ association). The presence of a more salient A during subsequent presentations of AX would aid in the perception of this stimulus as being more discriminable from other similar stimuli. Hall's (2003) proposal thus offers a possible explanation for why experience with two or more similar stimuli may improve discrimination between them, which is the essence of the phenomenon of perceptual learning. However, in order to explain the intermixed-blocked effect, this account requires the assumption that the withincompound associations responsible for the associative activation of a stimulus's unique features (and the corresponding process of enhancing their salience) are maintained better by intermixed than by blocked preexposure. Taken together, the results of the present experiments and those from our previous study (Rodríguez \& Alonso, 2014) speak against the validity of this assumption. It will be important for future work to clarify whether the greater capacity of blocked than of intermixed preexposure to maintain within-compound associations can also differentially affect the salience modulation of the stimulus features.

Author note This research was supported by grants from the Spanish Ministerio de Economía y Competitividad (Grant No. PSI2011-2431) and Gobierno Vasco (Grant No. IT-694-13). The authors thank to the Servicios Generales de Investigación (SGIker) of the UPV-EHU for personal and technical support.

\section{References}

Bakeman, R., \& McArthur, D. (1996). Picturing repeated measures: Comments on Loftus, Morrison, and others. Behavior Research Methods, Instruments, \& Computers, 28, 584-589. doi:10.3758/ BF03200546

Bennett, C. H., \& Mackintosh, N. J. (1999). Comparison and contrast as a mechanism of perceptual learning? Quarterly Journal of Experimental Psychology, 52B, 253-272.

Blair, C. A. J., \& Hall, G. (2003). Perceptual learning in flavor aversion: Evidence for learned changes in stimulus effectiveness. Journal of Experimental Psychology: Animal Behavior Processes, 29, 39-48.

Dwyer, D. M., Hodder, K. I., \& Honey, R. C. (2004). Perceptual learning in humans: Roles of preexposure schedule, feedback, and discrimination assay. Quarterly Journal of Experimental Psychology, 57B, 245-259.

Gibson, E. J., \& Walk, R. D. (1956). The effect of prolonged exposure to visually presented patterns on learning to discriminate them. Journal of Comparative and Physiological Psychology, 49, 239-242.

Hall, G. (1991). Perceptual and associative learning. Oxford, UK: Oxford University Press, Clarendon Press.

Hall, G. (1996). Learning about associatively activated representations: Implications for acquired equivalence and perceptual learning. Animal Learning \& Behavior, 24, 233-255.

Hall, G. (2003). Learned changes in the sensitivity of stimulus representations: Associative and nonassociative mechanisms. Quarterly Journal of Experimental Psychology, 56B, 43-55.

Hall, G., Blair, C. A. J., \& Artigas, A. A. (2006). Associative activation of stimulus representations restores lost salience: Implications for perceptual learning. Journal of Experimental Psychology: Animal Behavior Processes, 32, 145-155. doi:10.1037/0097-7403.32.2.145 
Honey, R. C., Bateson, P., \& Horn, G. (1994). The role of stimulus comparison in perceptual learning: An investigation with the domestic chick. Quarterly Journal of Experimental Psychology, 47, 83-103.

Honey, R. C., \& Hall, G. (1989). Acquired equivalence and distinctiveness of cues. Journal of Experimental Psychology: Animal Behavior Processes, 16, 178-184.

Hull, C. L. (1939). The problem of stimulus equivalence in behavior theory. Psychological Review, 46, 9-30. doi:10. 1037/h0054032

Lavis, Y., \& Mitchell, C. J. (2006). Effects of preexposure on stimulus discrimination: An investigation of the mechanisms responsible for human perceptual learning. Quarterly Journal of Experimental Psychology, 59, 2083-2101.

McLaren, I. P. L., \& Mackintosh, N. J. (2000). An elemental model of associative learning: I. Latent inhibition and perceptual learning. Animal Learning and Behavior, 28, 211-246.

Miller, N. E., \& Dollard, J. C. (1941). Social learning and imitation. New Haven, CT: Yale University Press.

Mitchell, C., \& Hall, G. (2014). Can theories of animal discrimination explain perceptual learning in humans? Psychological Bulletin, 140, 283-307.

Mundy, M. E., Honey, R. C., \& Dwyer, D. M. (2007). Simultaneous presentation of similar stimuli produces perceptual learning in human picture processing. Journal of Experimental Psychology: Animal Behavior Processes, 33, 124-138. doi:10.1037/0097-7403.33.2.124
Nelson, J. B., \& Sanjuan, M. C. (2009). Perceptual learning in a human conditioned suppression task. International Journal of Comparative Psychology, 22, 206-220.

Rescorla, R. A., \& Cunningham, C. L. (1978). Within-compound flavor associations. Journal of Experimental Psychology: Animal Behavior Processes, 4, 267-275. doi:10.1037/0097-7403.4.3.267

Rescorla, R. A., \& Freberg, L. (1978). The extinction of within-compound flavor associations. Learning and Motivation, 4, 411-427.

Rodríguez, G., \& Alonso, G. (2004). Perceptual learning in flavouraversion learning: Alternating and blocked exposure to a compound of flavors and to an element of that compound. Learning and Motivation, 35, 208-220.

Rodríguez, G., \& Alonso, G. (2008). Stimulus comparison in perceptual learning: The roles of sensory preconditioning and latent inhibition. Behavioural Processes, 77, 400-404.

Rodríguez, G., \& Alonso, G. (2014). Differential effect of the intermixed and blocked preexposure schedules on the strength of the withincompound associations. Journal of Experimental Psychology: Animal Learning and Cognition, 40, 327-334. doi:10.1037/ xan0000026

Rodríguez, G., Lombas, A. S., \& Alonso, G. (2009). Perceptual learning in conditioned taste aversion: Analysis of the effect of stimulus presentation. Psicológica, 30, 27-40.

Symonds, M., \& Hall, G. (1995). Perceptual learning in flavor aversion conditioning. Learning and Motivation, 26, 203-219. 